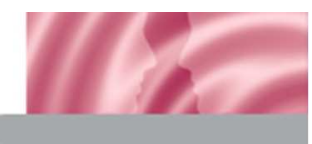

\title{
Adolescents' and parents' views of Child and Adolescent Mental Health Services (CAMHS) in Ireland
}

\begin{tabular}{|r|l|}
\hline Journal: & Journal of Psychiatric and Mental Health Nursing \\
\hline Manuscript ID: & Draft \\
\hline Manuscript Type: & Original Article \\
\hline Keywords: & $\begin{array}{l}\text { User Involvement, Child and Adolescent, Qualitative Methodology, } \\
\text { Carers/Families, Communication }\end{array}$ \\
\hline \multicolumn{2}{|l}{} \\
\hline
\end{tabular}

\section{SCHOLARONE ${ }^{\text {Tw }}$ \\ Manuscripts}




\author{
Adolescents' and parents' views of Child and Adolescent Mental Health Services \\ (CAMHS) in Ireland
}

\begin{abstract}
Aim: To explore adolescents' and parents' experiences of CAMHS in relation to accessibility, approachability, and appropriateness.

Methods: Using a descriptive qualitative design, a combination of focus group and single interviews were conducted with adolescents $(n=15)$ and parents $(n=32)$ from three mental health clinics. Data were transcribed verbatim and analysed using thematic analysis.
\end{abstract}

Results: Accessing mental health services was a challenging experience due to knowledge deficit, lack of information and limited availability of specialist services. Participants desired more information, involvement in decision-making, single and shared consultations, flexible scheduling of appointments, continuity with clinicians, school support and parent support groups. Participants seem to be generally satisfied, however adolescents felt less involved in decision making than they would have liked. Frequent staff changes was problematic as it disrupted continuity of care and hindered the formation of a trusting relationship.

\title{
Implications for practice
}

Parents and adolescents expressed similar views of the positive and negative aspects of mental health services. Their need for more information-sharing and involvement in decision-making underline the importance of collaborative practice. Clinician continuity contributed to trusting therapeutic relationships and was valued. These are key principles that with attention, could lead to quality service provision for adolescents and families.

Keywords: Adolescence, user participation, parents, services, mental health, qualitative methodology. 


\section{Accessible summary}

\section{What is known on the subject}

- We do not enough about adolescents and parents' experiences of attending child and adolescent mental health clinics in Ireland.

- We need to ensure that services for adolescents and parents are user-friendly, designed around their needs, accessible and effective.

\section{What this paper adds to existing knowledge}

- Lack of information and availability of services made it difficult for participants to access help for mental health issues.

- Joint appointments hindered open disclosure, with both parents and adolescents preferring time alone with professionals.

- Adolescents wanted to be included in information-sharing and decisionmaking, but some felt that their voices were not heard in the decision-making process.

\section{What are the implications for practice}

- Both adolescents and parents find it difficult to disclose feelings and build trust, so a consistent relationship with a professional is essential.

- Provision of flexible consultations (both single and shared), coupled with inclusion in information-sharing and decision-making would help improve the experience for adolescents and parents. 


\section{Introduction}

To ensure quality care, CAMHS teams need to place the adolescent ${ }^{1}$ and family at the heart of the service and work in partnership with them to deliver accessible and community-based mental health (Department of Health, 2008). Government departments and organisations have a responsibility to promote meaningful participation for adolescents and families (Sinclair, 2004) and to promote choice, partnership and involvement for families in child and adolescent mental health services (CAMHS) (Department of Health, 2006, James, 2007, Department of Health, 2008, Mental Health Foundation, 2009). Community child and adolescent mental health teams are the first line of specialist mental health services with adolescents the most frequent attenders (Health Service Executive, 2012). Some research suggests that parents' experiences are influenced by clinics' accessibility, level of involvement, and understanding of the services (Bjorngaard, et al., 2008, Holmboe, et al., 2011). Service users' participation is an essential indicator of quality of care and caregiver participation has been associated with better outcomes for adolescents (Fawley-King, et al., 2013). Parents' and adolescents' satisfaction with services has been strongly linked to functional improvement, diminished symptoms (Garland, et al., 2007, Ronzoni and Dogra, 2012) and completion of treatment (Oruche, et al., 2014).

Although there is increasing demand for user involvement, person-centred care and participation in service development and delivery worldwide, there remains a significant gap in the evidence base (Patel, et al., 2007, Day, 2008). Studies that

1 Children' is commonly used to encompass the age range of 0-18 years. In this paper, the term 'adolescents' seems more appropriate as participants were 11-17 years. Adolescents includes the term 'young people' to avoid cumbersome phrases. 
include adolescents in the evaluation of CAMHS are relatively few (Claveirole, 2004, Dogra, 2005) and a recent review found only 13 relevant studies, mainly of poor methodological quality, and concluded that more studies were needed (WorrallDavies and Marino-Francis, 2008). Likewise in Ireland, only two studies have examined users' experiences of CAMHS (Teggart and Linden, 2006, Damodaran and Sherlock, 2013). Structured interviews with adolescents ( $n=22$, aged 4-16) revealed that their right to assent to treatment and participation in decisions were not often upheld (Damodaran and Sherlock, 2013). In a mixed methods study with parents/carers $(\mathrm{n}=14)$ and young people $(\mathrm{n}=11$, aged 14-20) in Northern Ireland, participants reported frustration with service accessibility, information provision, waiting times, incomplete services, fears of stigma, and wanted more involvement in information provisions and decision-making (Teggart and Linden, 2006). Research indicates that parents and their children have different mental health needs and evaluate services based on differing perspectives, therefore, it is vital to include both viewpoints in any evaluation of services (Garland, et al., 2007, Aarons, et al., 2010, Biering, 2010). Given the limited research in this area, we investigated adolescents' and parents' views of child and adolescent mental health services in Ireland. The primary objective was to identify key factors impacting both positively and negatively on participants' satisfaction with CAMHS.

\section{Methods}

Qualitative descriptive approach were used to conduct this study (Sandelowski, 2004). Interviews were seen as more suitable for accessing in-depth information rather than structured satisfaction surveys which tend to produce higher satisfaction rates (Barber, et al., 2006, Bjorngaard, et al., 2008). Focus groups can work well with adolescents as 
it can help them feel more comfortable and group format can encourage expression, aiding interactions and feeling less exposed (Day, et al., 2006, Coyne, et al., 2009). Focus groups may not suit all participants particularly in a mental health context, thus, we included the option of individual interviews. Ethical approval was granted by the lead institution and local health service ethics committees.

\section{Sample and recruitment}

Participants from three clinics located in three regions were invited to participate by clinic staff, who explained the study and obtained verbal consent. Prior to data collection, the researchers obtained written informed consent from participantsand assent from those under 18 years. Participants were advised that the care they received would not be affected by their participation and that support was available after each interview if required.

The interview schedule contained open questions on services accessibility, availability, and appropriateness. Nine focus groups (six with parents and three with adolescents) and ten interviews (four with parent (s) and six with adolescents) were conducted. Interviews lasted approximately 30-90 minutes and were conducted by a psychologist/ social worker and nurse researcher. Recruitment of new participants ceased once data saturation had occurred. Final sample included 32 parents (6 male and 26 female) and 15 adolescents (6 male and 9 female). Adolescents (11-17 years) had been attending for an average of 23.57 months $(S D=23.30, N=14$, range 5-90 months). Five had a mood disorder, three had Attention Deficit Hyperactivity Disorder (ADHD) and remaining diagnoses included impulse control, anxiety, adjustment and behavioural disorders. 


\begin{abstract}
Data Analysis
Interviews were audio recorded and transcribed verbatim. Data were analysed by systematically identifying and grouping codes and categories into themes (Braun and Clarke, 2006). Transcripts were read to identify commonly occurring codes which were extracted into a table and then grouped into core categories according to similarity of content. The initial analytic framework was independently checked by two members of the team and then the remainder of data coded. The framework was refined throughout the analysis. An independent review of the final themes and process was conducted by the lead researcher to enhance the trustworthiness of the analysis (Sandelowski, 1993, Morse, et al., 2001).
\end{abstract}

\title{
Results
}

The analysis resulted in five themes: (1) Getting help, (2) Being heard and voicing opinions, (3) Building a therapeutic alliance, (4) Impact of stigma, and (5) Meeting support needs. Table 1 displays the themes and categories supported with participants' statements.

\section{Theme 1: Getting help}

Seeking help for a child who is experiencing mental health difficulties proved challenging for parents. For many, this was their first experience and they reported being unsure where to access help. Parents mentioned consulting with family members, teachers, and other acquaintances for advice about services. General practitioners (GPs) and private counsellors were typically the first point of contact for help. Parents were critical of the length of time it took to access CAMHS, which in 
some cases extended to 18 months. Several parents had been advised that they could access support much quicker by going to private services or asking their GP to write an urgent referral letter. Waiting for an appointment proved to be a particularly stressful time for parents. There was a perception that this concern was not shared by those in the CAMHS and in one clinic, parents felt that those who made a fuss often got an appointment quicker than those who stayed silent. These same concerns were not evident in the adolescents' data. It emerged that many were unaware they would be attending CAMHS until just prior to their first appointment, suggesting they were not involved in this part of the decision-making process.

\section{Theme 2: Being heard and voicing opinions}

Some parents felt fully informed by healthcare professionals (HCPs) on all aspects of their child's care and that their opinions and requests were listened to, while others felt suboptimally involved. These parents felt they had to fight for their voices to be heard or to obtain information on their child's progress. They did not feel empowered to question their child's care, to raise specific issues and felt pressured into accepting HCP's advice. Similarly some adolescents also felt at the periphery or excluded from the decision-making process, and did not feel empowered to voice their views.

Shared consultations were problematic. Both adolescents and parents felt it was important to be heard and be able to express views during sessions. However, they reported feeling inhibited speaking in front of each other and often engaged in selfcensorship. Parents noted that sometimes they had to say things they would rather their child did not hear. They worried that speaking openly may hinder their child's progress or would cause them to lose their child's trust. Consequently, they reported 
limiting what they shared and/or asking to speak to the HCP alone. Similarly adolescents were sometimes unwilling or unable to speak openly with a parent present and preferred separate consultations with HCPs. Some teams did provide opportunities for parents and adolescents to speak privately with HCPs; however this did not happen in all cases.

\section{Theme 3: Building a therapeutic alliance}

Both parents and adolescents spoke about the importance of building a trusting and therapeutic relationship with HCPS. A non-judgemental approach was considered very important. Some parents felt uncomfortable speaking about personal issues with strangers whilst others felt their parenting style was under scrutiny. Parents remarked that their children experienced difficulty talking openly with others and expressing thoughts and feelings. Those that felt that the process did not connect with their child suggested that professionals should try to establish a better rapport to encourage them to 'open up'. Likewise adolescents also stated that at times it was difficult to talk to professionals. Some were aware that professionals were sensitive to these issues as they used different means of fostering communication, such as writing or drawing. For older adolescents though, painting or completing questionnaires could be frustrating.

Staff turnover was noted as a key issue that negatively impacted on the therapeutic alliance, particularly in the case of psychiatry registrars. Participants were given either very little or no prior notice that this change would happen. Frequent changes were problematic as professionals had different approaches to care and treatment, and families had to start "from scratch" to establish a rapport with a new HCP. Parents" 
statements underscored the negative impact of staff turnover on adolescents' participation efforts. Adolescents noted how difficult it was to 'open your heart' to someone, for that person to leave, and feeling exposed 're-telling' their story to a new professional.

\section{Theme 4: Impact of stigma}

Both parents and adolescents were sensitive to the stigma attached to mental illness, which made some feel reluctant to engage with services. Some parents concealed the fact that their child was attending CAMHS from friends and family members, sometimes at the request of the child. Deciding to disclose to another person that their child was experiencing mental health problems was not done lightly, if at all. Adolescents also mentioned a reluctance to tell others that they were attending CAMHS. Stigma was perceived by parents to be most obvious within schools. Although some parents were satisfied with the support they received from their children's schools (often coordinated in conjunction with CAMHS staff), others complained about teachers who lacked understanding of mental health issues and a unsupportive school system.

\section{Theme 5: Meeting support needs}

Most participants had very little, if any, previous experience with mental health services. It was clear that there was a significant amount of anxiety and uncertainty associated with engaging with mental health services. Support needs consisted of two distinct categories: informational and emotional. Many parents reported not knowing what to expect at the first appointment and suggested that information on the service and processes would help alleviate their anxiety. The perception of not having 
Adolescents' and parents' views 10

adequate information appeared to continue past the first appointment as few parents reported having the therapeutic process explained to them and almost none reported receiving a care plan.

Similarly adolescents wanted more information on what to expect before attending their first appointment. They remarked that they were given little or no information by their parent(s) prior to their appointment and their parents had not answered some of their questions. However, it is likely that parents could not provide this information as they were unaware what to expect themselves. Most adolescents reported feeling uninformed and unprepared before attending appointments which made them feel anxious. However over time, some noted that they received more information on the treatment process.

While HCPs were seen as important sources of information, parents reported that they would appreciate more psycho-education, including what they could do to help their child and if there were any particular behaviours or signs of distress they should be watching for. Some had attended courses provided by CAMHS which had helped them understand their child's condition and provided them with useful behaviour management strategies and opportunities to meet other parents in similar situations. Parents remarked that their child's condition had a significant impact on their own well-being and family life and that they would benefit from additional support separate to that being provided for their child. Parents sometimes blamed themselves and felt guilty, because they felt they should have noticed their child's difficulties sooner. 
Adolescents identified three sources of support: HCPs, parents and particular teachers. Those who spoke positively made reference to being kept well informed, included in the decision-making processes, encouraged to participate during consultations and actively listened too by the professionals. They preferred HCP's who were friendly, warm, genuine, trustworthy, and non-judgmental. They appreciated HCPs liaising with their schools to discuss strategies and explain their conditions to teachers.

\section{Discussion}

The findings indicate that accessing and engaging with mental health services was a challenging experience for parents and adolescents due to accessibility barriers, staff changes, stigma, and lack of information about services and procedures. These same factors have also been reported as negative factors worldwide (Street, 2004, Sayal, 2006, Plaistow, et al., 2014). Although changes are underway to improve CAMH services, a recent report (Health Service Executive, 2012) found significant variation in the distribution and resourcing of CAMHS across regions. The scarcity of resources for youth mental health is a serious concern as most mental disorders emerge in adolescence and early adulthood and Ireland has high rates of youth mental health problems and suicide (Lynch, et al., 2004, Illback and Bates, 2011). However the scarcity of adolescent specialist services, poor awareness of mental disorders and stigma are also major challenges worldwide (Patel, et al., 2007).

Although parents and adolescents expressed satisfaction with the services, they held both positive and negative views on care provision. They appreciated the therapy and help but lacked information about what to expect, the treatment process, philosophy of care and professionals' roles. They wanted information on the service structure and 
procedures prior to the first appointment. Parents needed more information on their child's care plan, condition, and more parenting courses on behaviour management. Some parents were satisfied with the support they received from their children's schools (co-ordinated by CAMHS staff), whilst others reported difficulty sourcing support and experienced stigma.

Sharing treatment sessions was problematic for both parents and adolescents because of privacy and confidentiality concerns which is relatively under-reported (Harper, et al., 2013). They reported feeling inhibited by each other's presence (parent or child), resulting in constrained communication. As seen earlier, most adolescents felt excluded from the initial decision to attend and reported limited involvement in care decisions. This is problematic as encouraging openness and building a sense of trust and shared goals are essential elements in building a strong therapeutic alliance which is an important predictor of treatment outcome (Day, 2008).

Consistency in service provision and the quality of the relationship between families and professionals was reported to have a significant impact on both parents and adolescents satisfaction levels. Frequent staff changes were problematic as it hindered development of trust and relationship building. The importance of consistency, trust, good relationships, and professionals' interpersonal qualities are consistent with studies from Ireland (Teggart and Linden, 2006, Damodaran and Sherlock, 2013), England (Buston, 2002, Street, 2004, Day, et al., 2006, Plaistow, et al., 2014) and worldwide (Mitchell-Lowe and Eggleston, 2009, Gulliver, et al., 2010). 


\section{Practice implications}

The format of consultations needs to accommodate both parents and adolescents' preferences to encourage free and open information exchange (Coyne, 2006, Coyne, 2008). Adolescents and parents should be offered the opportunity to be seen separately and then together. It is essential that adolescents feel enabled to share their views, and contribute to shared therapy goals. It is important that professionals are approachable, friendly, warm, non-judgemental as this positively impacts on adolescents' experiences (Kim, et al., 2012). Staff turnover needs to be addressed as consistency is a critical requirement for adolescents (Harper, et al., 2013). CAMHS teams need to ensure that the adolescent has a key worker. Nurses could be the key worker as they play a key role in providing increased continuity and advocacy for service users and their carers/ family members, and in health promotion in schools (Health Service Executive, 2012).

Coping with a child who has mental health difficulties affects parental well-being and the family dynamic (Harden, 2005, Oruche, et al., 2012) so parental psychoeducational support is crucial. Information should be provided in different formats to prepare, assist involvement and reduce misunderstandings and anxiety (Ross and Egan, 2004).The significant impact of stigma on adolescents and parents, alongside the impact of the adolescents' mental health difficulties, indicates that information, multi-agency communication and social support are essential (O'Reilly, et al., 2013).

\section{Limitations}

Participants were recruited by gatekeepers which may have biased the sample but participants did express both positive and negative experiences about services. Future 
studies should include larger sample of adolescents and parents, combine interviews with participatory techniques, and take a longitudinal approach.

\section{Conclusions}

In summary, participants desired more information, involvement in decision-making, collaboration on care plans and valued therapeutic relationships and clinician continuity. These same principles are outlined in A Vision for Change (Department of Health, 2006) which provides a comprehensive model of mental health service provision for Ireland, and are included in the new $i C A M H S$ National Quality Guidelines (Health Service Executive, 2013) encouraging auditing and evaluation of services, identification of service gaps and development of action plans to address deficits. Quality service provision for adolescents and families is critically important in light of the increasing prevalence of mental disorders in adolescents and the longterm consequences of untreated disorders. To date CAMHS annual reports have not collected outcome measures that allow clinicians and providers to establish whether service providers are meeting the needs of those attending. This study contributes new data on adolescents and parents' experiences and results have been shared with participating clinics and more widely. Professionals are aware of service users' need for inclusion but there is still much work to be done to promote true partnership in mental health services. 


\section{REFERENCES}

Aarons G.A., Covert J., Skriner L.C., Green A., Marto D., Garland A.F. and Landsverk J. (2010) The eye of the beholder: youths and parents differ on what matters in mental health services. Administration and Policy in Mental Health 37(6), 459-67.

Barber A.J., Tischler V.A. and Healy E. (2006) Consumer satisfaction and child behaviour problems in child and adolescent mental health services. J Child Health Care 10(1), 9-21.

Biering P. (2010) Child and adolescent experience of and satisfaction with psychiatric care: a critical review of the research literature. Journal of Psychiatric and Mental Health Nursing 17(1), 65-72.

Bjorngaard J., Wessel A., Osborg O. and Hanssen-Bauer K. (2008) User satisfaction with child and adolescent mental health services: impact of the service unit level. Social Psychiatry and Psychiatric Epidemiology $43(635-641$.

Braun V. and Clarke V. (2006) Using thematic analysis in psychology. Qualitative Research in Psychology 3(2), 77-101.

Buston K. (2002) Adolescents with mental health problems: what do they say about health services? Journal of Adolescence 25(2), 231-242.

Claveirole A. (2004) Listening to young voices: challenges of research with adolescent mental health service users. Journal of Psychiatric and Mental Health Nursing 11(3), 253-260.

Coyne I. (2006) Consultation with children in hospital: children, parents' and nurses' perspectives. Journal of Clinical Nursing 15(61-71.

Coyne I., Hayes E. and Gallagher P. (2009) Inclusion of hospitalized children in healthcare research: Ethical, practical and organisational challenges. Childhood 16(3), 413-429.

Coyne I., T. (2008) Children's participation in consultations and decision-making at health service level: a critical review of the literature. . International Journal of Nursing Studies 45(1682-1689.

Damodaran J. and Sherlock C. (2013) Child rights and Child and Adolescent Mental Health Services (CAMHS) in Ireland. Irish Journal of Medical Science 182(4), 723-7.

Day C. (2008) Children's and young people's involvement and participation in mental health care. Child and Adolescent Mental Health 13(1), 2-8.

Day C., Carey M. and Surgenor T. (2006) Children's key concerns: piloting a qualitative approach to understanding their experience of mental health care. Clin Child Psychol Psychiatry 11(1), 139-55.

Department of Health (2006) "A Vision for Change" Report of the Expert Group on Mental Health Policy. In. Department of Health, Dublin.

Department of Health (2008) Children and young people in mind: the final report of the National CAMHS Review. edn., pp. 1-118, Department of Health London

Dogra N. (2005) What do children and young people want from mental health services? Curr Opin Psychiatry 18(4), 370-3. 
Fawley-King K., Haine-Schlagel R., Trask E.V., Zhang J. and Garland A.F. (2013) Caregiver participation in community-based mental health services for children receiving outpatient care. Journal of Behavioral Health Services and Research 40(2), 180-90.

Garland A., Haine R. and Boxmeyer C. (2007) Determinates of youth and parent satisfaction in usual care psychotherapy. Evaluation and Program Planning 30(45 - 54.

Gulliver A., Griffiths K.M. and Christensen H. (2010) Perceived barriers and facilitators to mental health help-seeking in young people: a systematic review. BMC Psychiatry $10(113$.

Harden J. (2005) "Uncharted Waters": The Experience of Parents of Young People With Mental Health Problems. Qualitative Health Research 15(2), 207-223.

Harper B., Dickson J.M. and Bramwell R. (2013) Experiences of young people in a 16-18 Mental Health Service. Child and Adolescent Mental Health, n/a-n/a.

Health Service Executive (2012) Fourth Annual Child \& Adolescent Mental Health Service Report 2011-2012. In. HSE, Kildare

Health Service Executive (2013) Irish Child \& Adolescent Mental Health Service (iCAMHS) National Quality Guidelines Document. In. Health Service Executive Dublin.

Health Service Executive (2012) A Vision for Psychiatric/ Mental Health Nursing. In, pp. 1-144. Health Service Executive,, Dublin

Holmboe O., Iversen H. and Hanssen-Bauer K. (2011) Determinants of parents' experiences with outpatient child and adolescent mental health services. International Journal of Mental Health Systems 5(1), 22.

Illback R.J. and Bates T. (2011) Transforming youth mental health services and supports in Ireland. Early Interv Psychiatry 5(22-27.

James A.M. (2007) Principles of youth participation in mental health services. Medical Journal of Australia 187(7 Suppl), S57-60.

Kim H., Munson M. and McKay M. (2012) Engagement in Mental Health Treatment Among Adolescents and Young Adults: A Systematic Review. Child and Adolescent Social Work Journal 29(3), 241-266.

Lynch F., Mills C., Daly I. and Fitzpatrick C. (2004) Challenging times: a study to detect Irish adolescents at risk of psychiatric disorders and suicidal ideation. Journal of Adolescence 27(4), 441-51.

Mental Health Foundation (2009) Evaluation Of The Choice And Partnership Approach In Child And Adolescent MH Services In England. edn., pp. 1-102, The Mental Health Foundation, London.

Mitchell-Lowe M. and Eggleston M. (2009) Children as consumer participants of child and adolescent mental health services. The Royal Australian and New Zealand College of Psychiatrists 17(4), 287-90.

Morse J., M,, Swanson J., M, and Kuzel A., J. (2001) The nature of qualitative evidence. edn., pp. 317, Sage, Thousand Oaks.

O'Reilly M., Vostanis P., Taylor H., Day C., Street C. and Wolpert M. (2013) Service user perspectives of multiagency working: a qualitative study with children with educational and mental health difficulties and their parents. Child and Adolescent Mental Health 18(4), 202-209.

Oruche U.M., Downs S., Holloway E., Draucker C. and Aalsma M. (2014) Barriers and facilitators to treatment participation by adolescents in a community 
mental health clinic. Journal of Psychiatric and Mental Health Nursing 21(241-248.

Oruche U.M., Gerkensmeyer J., Stephan L., Wheeler C.A. and Hanna K.M. (2012) The Described Experience of Primary Caregivers of Children With Mental Health Needs. Archives of Psychiatric Nursing 26(5), 382-391.

Patel V., Flisher A., J, Hetrick S. and McGorry P. (2007) Mental health of young people: a global public-health challenge. Lancet 369(1302-13.

Plaistow J., Masson K., Koch D., Wilson J., Stark R.M., Jones P.B. and Lennox B.R. (2014) Young people's views of UK mental health services. Early Interv Psychiatry 8(1), 12-23.

Ronzoni P. and Dogra N. (2012) Children, adolescents and their carers' expectations of child and adolescent mental health services (CAMHS). International Journal of Social Psychiatry 58(3), 328-36.

Ross N. and Egan B. (2004) 'What do I have to come here for, I'm not mad ?' Children's perceptions of a child guidance clinic. Clin Child Psychol Psychiatry9), 107-115.

Sandelowski M. (1993) Rigor or rigor mortis: the problem of rigor in qualitative research revisited. Advances in Nursing Science 16(2), 1-8.

Sandelowski M. (2004) Using qualitative research. Qualitative Health Research $14(10), 1366-1386$.

Sayal K. (2006) Annotation: Pathways to care for children with mental health problems. Journal of Child Psychology and Psychiatry and Allied Disciplines 47(7), 649-59.

Sinclair R. (2004) Participation in practice: Making it meaningful, effective and sustainable. Children and Society 18(106 - 118.

Street C. (2004) In-patient mental health services for young people--changing to meet new needs? J R Soc Promot Health 124(3), 115-8.

Teggart T. and Linden M. (2006) Investigating Service Users' and Carers' Views of Child and Adolescent Mental Health Services in Northern Ireland. Child Care in Practice 12(1), 27-41.

Worrall-Davies A. and Marino-Francis F. (2008) Eliciting children's and young people's views of Child and Adolescent Mental Health Services: A systematic review of best practice. Child and Adolescent Mental Health 13(1), 9-15. 


\begin{tabular}{|c|c|c|c|}
\hline Themes & Categories & Parents' quotes & Adolescents' quotes \\
\hline $\begin{array}{l}\text { Theme 1: Getting } \\
\text { help }\end{array}$ & $\begin{array}{l}\text { Long waiting lists } \\
\text { Lack of information } \\
\text { about services } \\
\text { Feeling unprepared } \\
\text { Getting help }\end{array}$ & $\begin{array}{l}\text { FG3C-P3: I remember going to my own doctor crying and I } \\
\text { said, you have to do something you know? I'm sick listening } \\
\text { to the teachers, I've a path worn to the school, they all know } \\
\text { there's some kind of problem and she said the waiting list is } \\
\text { so long you're better off going privately. } \\
\text { INT-P3C: Oh } 100 \% \text { satisfied, I mean I couldn't be any } \\
\text { happier with the help that daughter got or the help that I got } \\
\text { because without them I don't know where I'd have been. }\end{array}$ & $\begin{array}{l}\text { FG1A-YP1: Well I like coming here cos everybody's } \\
\text { really friendly, like nobody's like real strict like, } \\
\text { they're all really nice }\end{array}$ \\
\hline $\begin{array}{l}\text { Theme 2: Being } \\
\text { heard and voicing } \\
\text { opinions }\end{array}$ & $\begin{array}{l}\text { Discussing choices } \\
\text { Lack of information } \\
\text { about treatment process } \\
\text { Feeling excluded } \\
\text { Difficulty with shared } \\
\text { consultations }\end{array}$ & $\begin{array}{l}\text { FG4B-P2 I think we met with the psychiatrist first and } \\
\text { she put some different options to us with regard to } \\
\text { [child] and then we discussed them with her and we let } \\
\text { her know what we were going to do' } \\
\text { FG6B-P1 I actually think it would be a good idea if parents } \\
\text { could have a private session just because anytime we went in } \\
\text { there, we had [child] with us. And while I suppose we learnt } \\
\text { how to talk about things because maybe we didn't before cos } \\
\text { we never had to deal with it, I think for me personally, I'd } \\
\text { have liked the opportunity to have half an hour or an hour } \\
\text { just about how do I really feel about this? What am I } \\
\text { supposed to be feeling? What was I doing wrong? }\end{array}$ & $\begin{array}{l}\text { INT-YP3A: I feel like everyone just kind of talks at } \\
\text { me or about me when I'm right there and they might } \\
\text { ask me is that ok and they ask me in such a way that I } \\
\text { kind of feel like I don't have any other option just to } \\
\text { agree with them } \\
\text { INT-YP2A Explain things better and like on your first } \\
\text { session don't be asking such personal questions } \\
\text { when there is loads of other people in the room cos } \\
\text { when I was brought in there were four counsellors } \\
\text { sitting there and a doctor who my parents met and } \\
\text { they were asking me really personal questions that I } \\
\text { didn't want to answer in front of my parents let alone } \\
\text { a load of strangers' }\end{array}$ \\
\hline $\begin{array}{l}\text { Theme 3: } \\
\text { Building a } \\
\text { therapeutic }\end{array}$ & $\begin{array}{l}\text { Building trust } \\
\text { Building relationships }\end{array}$ & $\begin{array}{l}\text { INT-P3C: You know it didn't matter what I said or what, you } \\
\text { know, what happened I had somebody there that I could talk } \\
\text { to and it wasn't an issue, I wasn't fobbed aside and I wasn't } \\
\text { ridiculed, my opinion and my feelings were of importance I } \\
\text { felt to them, they wanted to know } \\
\text { FG3B-YPI You see them for two weeks then you come back } \\
\text { and you find someone else. So it's weird and then they ask }\end{array}$ & $\begin{array}{l}\text { INT-YP4A You don't feel like your judged in anything } \\
\text { that your saying and I really like as well they } \\
\text { remember who you are...and for example my } \\
\text { psychologist she remembers everything that I tell her } \\
\text { like I start to tell her something and well she still lets } \\
\text { me talk } \\
\text { FG3C-YP2: It's very hard cos you're used to them, } \\
\text { or you're just getting used to them, and they go. It's a }\end{array}$ \\
\hline
\end{tabular}




\begin{tabular}{|l|l|}
\hline alliance & $\begin{array}{l}\text { Re-telling personal } \\
\text { history }\end{array}$ \\
\hline & \\
\hline
\end{tabular}

you the same questions the same person asked you two weeks ago and it's like, getting to know you again. It's like they don't know about you, like they can't read the file before you walk in the door. It's just like, sorry what's your name again?' It's frustrating.

Fear of being labelled FG4C-P3: I have told another person that had similar problems and that probably would be the only person I've
prother Keeping attendance

Theme 4: Impact of stigma secret

\begin{tabular}{|c|c|}
\hline (n) & teachers \& school \\
\hline $\begin{array}{l}\text { Theme 5: Meeting } \\
\text { support needs }\end{array}$ & $\begin{array}{l}\text { Informational support } \\
\text { needs } \\
\text { Emotional support needs } \\
\text { Parenting courses } \\
\text { helpful } \\
\text { Support from teachers \& } \\
\text { schools }\end{array}$ \\
\hline
\end{tabular}

told, certainly I'd have family members told that we're getting help but I wouldn't have told them that we're going to psychiatric services to avail of help because I don't think Ireland has moved that much further even now

INT-P2C: The last school where my son came from people gossip and stories manage to circulate so we did have trouble trying to find him a proper school and support. The school we chose has been great and I really thing that made the difference. I think the school was crucial because there was no support in his previous school.

FG2A-P1 It's a blind journey actually, the way it is, and I don't think it has to be blind, I think there could be a bit of a road map laid out there for you. To be told, this is what we might do or that could happen or that could happen. That the options are laid out for you so it's not a case of, I wonder what we're going to do this week, you know?

FG5C-P2 I did a parenting group and I found it was brilliant... we built up certainly a lot of stuff that we learnt on that course into our family. It helped us an awful lot'. real step you're opening your heart, you're exposing yourself and then they're gone and you're thinking God you were just getting to know them, you have to start all over again

FG3C-YP1: At the start I came here every week and it was every Tuesday and my friends would be like, where are you going? Cos they'd notice I was disappearing every week and they'd be like, where are you going? I'm going to a friends, leave me alone.

INT-YPIC When I first came to the building it was mental health that was my first time so when I first came I was worried and I said to my friend does that mean that I am mad?

FG3B-YP1: I have no idea. I actually don't know. I don't know who any of these people are. They just come in and say hi I'm [name], I'm [name], and it's like, hey

FG2C-YP2: If I'm having trouble in school or anything like if I'm having a bad day now, like [name], she set up something in school for me so I'd have someone to talk to about stuff so it's grand 
